\title{
Preventive effect of cocoa flavanols against glucotoxicity-induced vascular inflammation in the arteria of diabetic rats and on the inflammatory process in TNF- $\alpha$-stimulated endothelial cells.
}

David Álvarez-Cilleros ${ }^{1}$, María Elvira López-Oliva², Sonia Ramos ${ }^{1}$, María Ángeles Martín 1,3,*

${ }^{1}$ Departamento de Metabolismo y Nutrición, Instituto de Ciencia y Tecnología de los Alimentos y Nutrición (ICTAN), Consejo Superior de Investigaciones Científicas (CSIC), Madrid, Spain

${ }^{2}$ Departamento de Fisiología. Facultad de Farmacia, Universidad Complutense de Madrid (UCM), Madrid, Spain

${ }^{3}$ Centro de Investigación Biomédica en Red de Diabetes y Enfermedades Metabólicas Asociadas (CIBERDEM), Instituto de Salud Carlos III (ISCIII), Madrid, Spain.

* Corresponding author: amartina@ictan.csic.es

Departamento de Metabolismo y Nutrición, Instituto de Ciencia y Tecnología de los Alimentos y Nutrición (ICTAN), Consejo Superior de Investigaciones Científicas (CSIC), José Antonio Novais 10, Ciudad Universitaria, 28040, Madrid, Spain. Phone: +34.91 .544 .56 .07 . Fax: +34.91 .549 .36 .27$

1

\begin{abstract}
Abbreviations:
AUC, area under the curve; CVD, cardiovascular disease; COX-2, cyclooxigenase-2; DHBA, 2,3-dihydroxybenzoic acid; DHPAA, 3,4-dihydroxyphenylacetic acid; GTT, glucose tolerance test; HOMA-IR, homeostasis model assessment of insulin resistance; HPPA, 3-hydroxyphenylpropionic acid; ICAM-1, intercellular adhesion molecule-1; IL-6, interleukin-6; MCP-1, monocyte chemoattractant protein 1; NF- $\kappa \mathrm{B}$, nuclear factor-kappa $\mathrm{B}$; i-NOS, inducible nitric oxide synthase; ROS, reactive oxygen species; T2D, type 2 diabetes; TNF- $\alpha$, tumour necrosis factor- $\alpha$; ZDF, Zucker diabetic fatty; ZL, Zucker lean; VCAM-1, vascular endothelial growth factor 1 .
\end{abstract}




\begin{abstract}
Hyperglycaemia induces a vascular inflammatory process that is a critical event in cardiovascular disease in type 2 diabetes. Cocoa and its flavanols have been widely investigated for its antioxidant and anti-inflammatory properties, and several clinical and pre-clinical studies support their vascular benefits. However, the effects of cocoa flavanols on vascular inflammation in diabetes remain to be elucidated. Herein, we evaluated the antiinflammatory effect of a cocoa-rich diet on the aortas of Zucker diabetic fatty (ZDF) rats. Moreover, the potential role of flavanol-derived colonic metabolites to modulate the adhesion and inflammatory processes were also evaluated using TNF- $\alpha$-stimulated endothelial cells. Results demonstrate that cocoa attenuates the levels of phospho-p65nuclear factor-kappa $\mathrm{B}(\mathrm{NF}-\mathrm{\kappa} \mathrm{B})$ and the expression of inflammatory factors including intercellular adhesion molecule-1 (ICAM-1), vascular adhesion molecule-1 (VCAM-1) and inducible nitric oxide synthase in the aortas of ZDF rats. Experiments with endothelial cells further confirm that a mix of flavanol-derived colonic metabolites effectively down-regulate the levels of p-p65-NF- $\mathrm{B}$ and the cell adhesion molecules ICAM-1 and VCAM-1, preventing thus the increase of monocyte-endothelial adhesion induced by TNF- $\alpha$. These novel data provide the first evidence of the relevant role of cocoa and their flavanol-derived metabolites to avoid the development of endothelial inflammation and diabetic complications.
\end{abstract}

Keywords: Flavonoids-derived metabolites; NF- $\mathrm{BB}$; endothelial adhesion molecules; proinflammatory enzymes 


\section{Highlights}

- Cocoa rich diet prevent hyperglycaemia-induced arterial inflammation in diabetic rats

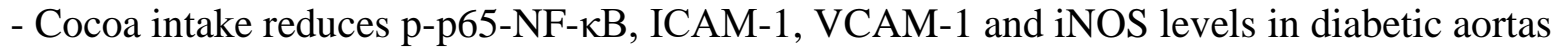

- Flavanol-derived gut metabolites protect endothelial cells against inflammation

- Flavanol colonic metabolites inhibit monocyte-endothelial adhesion induced by TNF- $\alpha$ 


\section{Introduction}

Type 2 Diabetes (T2D) is associated with a high risk of endothelial cell inflammation leading to cardiovascular complications such as atherosclerosis (Shah \& Brownlee, 2016). Indeed, cardiovascular diseases (CVDs) represent the major burden of mortality and morbidity in diabetic patients (García-Carro et al., 2019). Hyperglycaemia, a hallmark of diabetes, promotes inflammation by oxidative stress-induced activation of $\mathrm{NF}-\mathrm{KB}$ and the subsequent production of pro-inflammatory cytokines (La Sala et al., 2019). Increased expression of inflammatory factors including interleukin-6 (IL-6), tumour necrosis factoralpha (TNF- $\alpha$ ), intercellular adhesion molecule-1 (ICAM-1), vascular cell adhesion molecule-1 (VCAM-1), and other cytokines are among the most important molecular determinants that lead to vascular dysfunction (Xia et al., 2014). Therefore, targeting inflammatory pathways in the vascular system could be a decisive way to decrease cardiovascular risk in diabetes.

Healthy diets based on high consumption of plant-derived foods are closely associated with a significant decrease in the incidence and prevalence of chronic inflammatory disorders (Lapuente et al., 2019). This favourable effect has mainly been attributed to the presence of several bioactive compounds, such as phenolic compounds. Among these, flavonoids, abundant in fruits, vegetables, legumes and cocoa, have gained increased attention due to its anti-inflammatory properties (Santhakumar et al., 2018). Many epidemiological, in vitro and in vivo studies have shown promising results about the potential of flavonoids to prevent the onset and development of vascular inflammation (Fallah et al., 2020, Hussain et al., 2020, Toma et al., 2020). These effects appear to be mediated via several individual and synergistic mechanisms, such as the inhibition of key inflammatory mediators and pro-inflammatory enzymes, as well as the modulation of the 
expression and activity of pro-inflammatory cytokines (Soheila et al., 2019). Consequently, it has been suggested that flavonoids can play an important role in decreasing the risk of CVD in diabetes (Caro-Ordieres et al., 2020). Indeed, these natural compounds are considered to be as an interesting and cost-effective therapeutic alternative to alleviate vascular inflammation in diabetic patients.

Cocoa is a flavonoid-rich food widely investigated for its potential beneficial effects in chronic diseases related to inflammation and oxidative stress (Martin et al., 2017). In particular, cocoa intake has been related with numerous vascular protective effects, including lowering of blood pressure (BP) (Ferri et al., 2015), improving endothelial function (Grassi et al., 2015), as well as prevention of arterial stiffness (Alvarez-Cilleros et al., 2019). The favourable properties of cocoa has largely been ascribed to its flavonoids content, mainly monomeric flavanols such as epicatechin and catechin, as well as oligomeric procyanidins. Epicatechin have a Cmax of about 1 hour declining rapidly from the circulatory system after 2-4 hours following consumption of cocoa (Actis-Goretta et al., 2012). However, procyanidins and the fraction of epicatechin, which are not absorbed in the small intestine (more than $80 \%$ of cocoa flavanols), reach the colon where they are metabolized by the microbiota generating several phenolic metabolites, such as mono- and di-hydroxylated phenylpropionic, phenylacetic and hydroxybenzoic acids and their conjugated form (sulphates and glucuronidates) (Mayorga-Gross et al., 2019). These small phenolic acids have a delayed Cmax of about 6 hours and longer half-life $\left(\mathrm{T}_{1 / 2}\right)$ values that ranged from 3.1-7.6 $\mathrm{h}$ (Ottaviani et al, 2016). In this sense, we have previously showed that flavanol-derived colonic metabolites such as 3,4-dihydroxyphenylacetic acid (DHPAA), 2,3dihydroxybenzoic acid (DHBA) and 3-hydroxyphenylpropionic acid (HPPA) were able to improve endothelial function and prevent oxidative stress in human endothelial cells 
(Álvarez-Cilleros et al., 2018). These findings suggest that microbial derived metabolites play an important role in conferring the vascular benefits of cocoa flavanols. However, the potential effects of cocoa flavanols and their gut derived metabolites on vascular inflammation in diabetes remain to be elucidated.

Considering this, in the present study, we evaluated the anti-inflammatory effect of a cocoa-rich diet on the aortas of Zucker diabetic fatty (ZDF) rats, a widely used model of T2D. In addition, the potential role of flavanols-derived colonic metabolites to modulate the adhesion and inflammatory processes were also evaluated using TNF- $\alpha$-stimulated endothelial cells, a widely used model of vascular inflammation. 


\section{Material and Methods}

\subsection{Materials and Chemical}

3,4-(DHPAA), 2,3-(DHBA), 3-(HPPA), gentamicin, penicillin G, streptomycin, bovine serum albumin (fraction V), 6-[4-(2-piperidin-1-ylethoxy)phenyl]-3-pyridin-4ylpyrazolo[1,5-a]pyrimidine (Comp C) and LY294002 (LY) were purchased from Sigma Chemical (Madrid, Spain). Recombinant murine tumour necrosis factor TNF- $\alpha$ was obtained from Preprotech (Madrid, Spain). The fluorescent probes 4-amino-5-methylamino-2,7difluorofluorescein diacetate (DAF-FM-DA) and Calcein-AM were from Molecular Probes (Eugene, OR). Anti-TNF- $\alpha$ (sc-52746), anti-IL-6 (sc-57315), anti-monocyte chemoattractant protein 1 (MCP-1, sc-52701), anti-phospho-Ser536-p65-NF-кB (sc-135769), anti-inducible nitric oxide synthase (iNOS, sc-651), anti-cyclooxigenase-2 (COX-2, sc-19999), antiVCAM-1 (sc-13160), and anti-ICAM-1 (sc-107) were purchased from Santa Cruz (Qimigen, Madrid, Spain), and $\beta$-actin was from Cell Signaling Technology (Izasa, Madrid, Spain). Materials and chemicals for electrophoresis and the Bradford reagent were from BioRad (BioRad Laboratories S.A., Madrid, Spain). Cell culture dishes were from Falcon (Cajal, Madrid, Spain), and cell culture medium and foetal bovine serum were from Lonza (Madrid, Spain).

\subsection{Diet and Animals}

Cocoa rich-diet (10\%) was produced by adding $100 \mathrm{~g} / \mathrm{Kg}$ of natural Forastero cocoa powder (a kind gift from Idilia Foods, Barcelona, Spain) to a control AIN-93G diet (Panlab S.L., Barcelona, Spain) at the expense of starch and cellulose, thus the cocoa diet was corrected by carbohydrate and fibre but not by protein or fat. As a result, the cocoa diet was 
slightly richer in proteins $(2,2 \%)$ and lipids $(1,1 \%)$ but, in order to make both diets isocaloric $(15048 \mathrm{~kJ} / \mathrm{kg})$, the content in carbohydrate was slightly reduced $(4,2 \%)$. The total polyphenol content of the cocoa was determined by the spectrophotometric method of FolinCiocalteu using gallic acid as the standard and main cocoa flavonoids and theobromine were determined by LC-MS as previously described (Alvarez-Cilleros et al., 2019). The polyphenolic profile of the cocoa powder showed that monomeric epicatechin and catechin were the major flavanols in the extract, together with appreciable amounts of procyanidins B1 and B2. Theobromine was also present in high amounts. The resulting cocoa diet was isoenergetic and its composition is given in Table 1

Nine-week-old male Zucker diabetic fatty rats $(Z D F, n=16)$ and their Zucker lean controls (ZL, $\mathrm{n}=6)$ were purchased from Charles River Laboratories (L'arbresle, France) and were placed under controlled conditions $\left(21^{\circ} \mathrm{C} \pm 1^{\circ} \mathrm{C}, 50-60 \%\right.$ humidity and $12 \mathrm{~h}$ light/dark cycles). After one week of acclimation (at 10 weeks of age), ZDF diabetic rats were randomly divided into two groups of eight animals that received the standard AIN-93G diet (ZDF-C) or the same control diet supplemented with $10 \%$ of cocoa (ZDF-Co) for 10 weeks. The lean Zucker rats (ZL) received the standard AIN-93G diet. During the study, all experimental groups were provided with food and water ad libitum. There was no differences in daily food intake between diabetic rats fed with cocoa (ZDF-Co) and their corresponding diabetic control animals (ZDF-C). Animals were treated according to the European (2010/63/EU) and Spanish (RD 53/2013) legislation on Care and Use of Experimental Animals and the experiments were approved by the Ethics Committee from Comunidad de Madrid (PROEX 304/15).

At 20 weeks of age, animals were sacrificed and the aorta was resected for immunohistochemical analysis. Glucose was determined in blood samples using an Accounted 
Glucose Analyzer (LifeScan España, Madrid, Spain) and insulin and glycosylated haemoglobin (HbA1c) were quantified by ELISA kits (Rat Insulin, Mercodia, Uppsala, Sweden; HbA1c Kit Spinreact, BioAnalitica, Madrid, Spain). Fasting plasma concentrations of both glucose and insulin were used to calculate the insulin resistance index [homeostasis model assessment (HOMA)-IR] using the following formulae: HOMA-IR=fasting insulin (mU/ml) X fasting glucose (mM)/22.5. Triacylglycerols (TG), HDL-Cholesterol (HDL-Cho) and LDL-Cho were determined in serum by kits (BioSystems, Madrid, Spain) as described elsewhere (Alvarez-Cilleros et al., 2019). Tumour necrosis factor- $\alpha$ (TNF- $\alpha$ ) and interleukin-6 (IL-6) levels were quantified in serum samples by specific rat TNF- $\alpha$ Quantikine ELISA Kit (RTA00, R\&D System, USA) and IL-6 DuoSet ELISA Kit (DY506, R\&D System, USA) according to the manufacturer's instruction.

\subsection{Immuno-histochemical analysis}

For histological analysis, aortic samples were fixed in paraformaldehyde (4\%), embedded in paraffin, and cut into 4- $\mu$ m-thick sections. Antibodies against TNF- $\alpha$, IL-6, MCP-1, ICAM-1, VCAM-1, p-p65-NF- $\mathrm{B}$, iNOS and COX-2, were used. Serial aortic sections were incubated with the primary antibodies overnight at $4{ }^{\circ} \mathrm{C}$ and then with a biotin-conjugated secondary antibody and streptavidin-biotin peroxidase for 30 min. Substrate used was $0.05 \%$ 3,3'-diaminobenzidine tetrahydrochloride (DAB) and a brown colour was detected and regarded as a positive signal under a light microscope. For the immunoreactive score, ten samples were selected at random and viewed under high magnification (x400; Leica DM LB2 microscope and a digital Leica DFC 320 camera (Leica)). Specimens were scored as positive when the cytoplasm contained yellow or brown particles. The intensity of immunostaining for each antibody was evaluated according four 
semi-quantitative immunohistochemistry categories reported as negative (0), weak (1+), moderate (2+), strongly (3+) and very strong (4+) stained cells.

\subsection{Cell culture and treatments}

Human endothelial cell line EA.hy926 and Human Monocyte cell line TPH-1 were a gift from Prof. Dr. Patricio Aller and Dr. Carmelo Bernabeu, (Centro de Investigaciones Biológicas, CSIC, Madrid, Spain). Cells were maintained in a humidified incubator containing 5\% $\mathrm{CO} 2$ and $95 \%$ air at $37^{\circ} \mathrm{C}$ and were grown in DMEM media (EA.hy926) or RPMI (TPH-1), supplemented with $10 \%$ foetal bovine serum (FBS) and $1 \%$ of the following antibiotics: gentamicin, penicillin and streptomycin. Different microbial metabolites DHPAA, DHBA and HPPA $(10 \mu \mathrm{M})$ and a mixture of microbial metabolites (MIX) at $4 \mu \mathrm{M}$ each one $(4 \mu \mathrm{M}$ of DHPAA $+4 \mu \mathrm{M}$ of DHBA $+4 \mu \mathrm{M}$ of HPPA $)$ were diluted in DMEM culture medium. For the TNF- $\alpha$ treatment, different concentrations of TNF- $\alpha(50,100$ and $500 \mathrm{ng} / \mathrm{mL}$ ), diluted in serum-free culture medium were added to the EA.hy926 cells during 18 hours. In the experiments with metabolites and TNF- $\alpha$, EA.hy926 cells were first preincubated for $6 \mathrm{~h}$ with DHPAA, DHBA, HPPA and the MIX and after that the proinflammatory TNF- $\alpha(50 \mathrm{ng} / \mathrm{mL})$ was added for $18 \mathrm{~h}$.

\subsection{Evaluation of cell viability}

Cell viability was determined by using the crystal violet assay. EA.hy926 cells were seeded at low density $\left(2 \times 10^{5}\right.$ cells per well) in 24 -well plates. After the TNF $\alpha$ treatment, cells were incubated with crystal violet $(0.2 \%$ in ethanol) for 20 min. Plates were rinsed with distilled water, allowed to dry, and $1 \%$ sodium dodecyl sulfate (SDS) added. The 
absorbance of each well was measured using a microplate reader at $570 \mathrm{~nm}$ (Bio-Tek, Winooski, VT, USA).

\subsection{Determination of interleukin-6 (IL-6) secretion by endothelial cells}

Concentration of IL-6 in cell culture supernatants was determined using a human IL-6 ELISA kit of Thermo Fisher Scientific Inc (Madrid, Spain) according to manufacturer's instructions. The ELISA 96-well micro plates were analysed using a microplate reader at 570 nm (Bio-Tek, Winooski, VT, USA).

\subsection{Preparation of cell lysates for Western blotting}

To detect iNOS, COX-2, p-p65-NF-кB, IL-6, ICAM-1 and VCAM-1, cells were lysed at $4{ }^{\circ} \mathrm{C}$ in a buffer containing $25 \mathrm{mM}$ HEPES (pH 7.5), $0.3 \mathrm{M} \mathrm{NaCl}, 1.5 \mathrm{mM} \mathrm{MgCl}$, $0.2 \mathrm{mM}$ EDTA, $0.5 \mathrm{mM}$ 1,4-Dithiothreitol, $0.1 \%$ Triton $\mathrm{X}-100,200 \mathrm{mM} \quad$ Bglycerolphosphate, $0.1 \mathrm{mM} \mathrm{Na} \mathrm{VO}_{4}, 2 \mu \mathrm{g} / \mathrm{mL}$ leupeptin, and $1 \mathrm{mM}$ PMSF. Supernatants

were collected, assayed for protein concentration by using the Bradford reagents, aliquoted and stored at $-80{ }^{\circ} \mathrm{C}$ until used for Western blot analyses.

\subsection{Protein determination by Western Blotting}

Equal amounts of protein $(100 \mu \mathrm{g})$ were separated by SDS-PAGE and transferred to polyvinylidene difluoride filters (Protein Sequencing Membrane, BioRad). Membranes were probed with the corresponding primary antibody followed by incubation with peroxideconjugated antirabbit Ig (GE Healthcare, Madrid, Spain). Blots were developed with the ECL system (GE Healthcare). Normalization of Western blot was ensured by $ß$-actin and bands were quantified using a scanner and accompanying software. 


\subsection{Monocyte adhesion assay}

The monocyte adhesion assay was performed as previously described (Ha et al., 2018). THP-1 cells were labelled with Calcein-AM at a final concentration of $7.5 \mu \mathrm{M}$ for 30 min at $37^{\circ} \mathrm{C}$ and $5 \% \mathrm{CO}_{2}$. Labelling was stopped by adding RPMI medium and cells were washed twice with PBS and resuspended in RPMI. Prior the adhesion assay, endothelial cells were pre-treated with or without the MIX for 6 hours and stimulated with $50 \mathrm{ng} / \mathrm{mL}$ of TNF $\alpha$ for 18 hours. After that, THP-1 cells labelled with Calcein-AM were co-incubated with EA.hy 926 treated cells for $60 \mathrm{~min}$ at $37^{\circ} \mathrm{C}$ and $5 \% \mathrm{CO}_{2}$. Next, to remove non-adherent THP-1, cells were washed with PBS and excess liquid blotted onto filter paper. This was repeated three times and then $1 \mathrm{~mL}$ of PBS was added to the plates. Fluorescence intensity was monitored at $488 \mathrm{~nm}$ excitation and $515 \mathrm{~nm}$ emissions using a fluorescence microplate reader (Bio-Tek, Winooski, VT, USA). The attachment of THP-1 cells was also confirmed under an inverted fluorescence Leica AF6000 LX microscope (excitation wavelength: 488 $\mathrm{nm}$; emission wavelength: $515 \mathrm{~nm}$ ).

\subsection{Statistics}

Prior to statistical analysis, data were tested for homogeneity of variances by the test of Levene; for multiple comparisons, one-way ANOVA was followed by a Tukey test when variances were homogeneous or by the Tamhane test when variances were not homogeneous. The level of significance was $\mathrm{P}<0.05$. A GraphPad Prism version 7.00 (GraphPad software, Inc., La Jolla, California) was used. 


\section{Results}

\subsection{Cocoa intake decreases arterial inflammation in diabetic rats}

After 10 weeks of treatment, body weight and total food and energy intake were increased in both groups of ZDF rats in comparison with ZL animals (Table 2). However, the enhancement in body weight of ZDF-Co rats was significantly lesser than that of ZDF-C rats; consequently, both food efficiency and energy efficiency were $40 \%$ lower in the ZDFCo group. This reduced energy/food efficiency seems to be related to the ability of cocoa flavanols to inhibit digestive enzymes leading to slow carbohydrate digestion and absorption. The metabolic characteristics of the animals are shown in Table 3. At 20 weeks of life, ZDF animals presented hyperglycaemia, hyperinsulinemia and increased levels of HbA1c and insulin resistance (HOMA-IR). All these parameters were significantly improved in diabetic animals that were supplemented with cocoa. On the contrary, HDLCho, LDL-Cho and TG levels were significantly elevated in both diabetic ZDF groups in comparison to the ZL group.

In order to investigate whether cocoa supplementation could affect vascular inflammation in ZDF rats, levels of pro-inflammatory cytokines, such as IL-6 and TNF- $\alpha$ were measured in aortic tissue by immunohistochemistry (Figures 1A and 1B). Results indicated that levels of IL-6 were significantly increased in ZDF-C rats as compared to ZL group. Interestingly, cocoa diet significantly reduced the expression level of this proinflammatory cytokine, showing that cocoa intake may counteract the low grade of inflammation found in diabetic ZDF animals. On the contrary, no differences were found in the levels of TNF- $\alpha$ among all animal groups. Likewise, circulating levels of these cytokines in serum were not significantly different among ZL, ZDF-C and ZDF-Co rats (Fig. 1C). 


\subsection{Cocoa diet prevents enhance ICAM-1 and VCAM-1 expressions in arteries of}

diabetic animals

Following, we explore the effect of cocoa on the expression of ICAM-1, VCAM-1 and MCP-1 that can contribute to vascular inflammation. We measured their expression in the aorta by immunohistochemistry and found that the levels of ICAM-1 and VCAM-1 were significantly increased in the aorta of untreated ZDF rats compared with non-diabetic ZL rats (Figure 2A and 2B). However, ZDF-Co showed significantly reduced expression levels of both mentioned adhesion molecules. There were no differences in MCP-1 staining among the three groups (Figure 2C). These results further substantiated that cocoa supplementation exerts an anti-inflammatory activity in the diabetic vascular tissue.

\subsection{Cocoa diet prevents increased NF-кB phosphorylation and iNOS expression in arteries of diabetic animals}

During vascular inflammation, gene expression of cytokines and adhesion molecules in vascular tissues is regulated by NF- $\kappa$ B. Therefore, we next investigated the effect of the

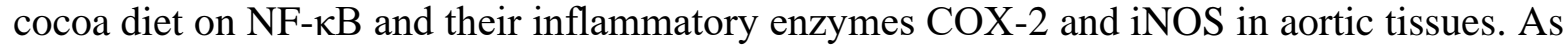
shown in figure $3 \mathrm{~A}, \mathrm{ZDF}-\mathrm{C}$ rats had markedly increased levels of p-p65 NF- $\kappa \mathrm{B}$ positive staining in the aorta section compared to ZL rats. However, the p-p65 NF- $\kappa B$ staining was significantly reduced in aortic tissues of ZDF-Co animals. Likewise, the levels of iNOS were significantly increased in diabetic ZDF rats whereas cocoa supplementation considerably decreased iNOS staining in the aorta of ZDF-Co rats (Figure 3B). No differences were observed in COX-2 among all animal groups (Figure 3C). Altogether, these results indicate that cocoa diet exhibit anti-inflammatory properties via potentially

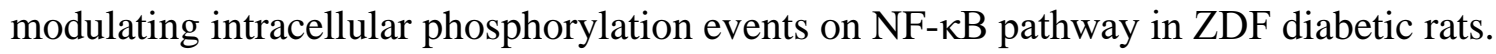




\subsection{Cocoa flavanol metabolites protect endothelial cells against TNF- $\alpha$ induced inflammation}

In order to study whether cocoa metabolites from flavanols may be responsible of the beneficial effects of cocoa in diabetic animals, we investigated their anti-inflammatory effect using an in vitro model of TNF- $\alpha$-stimulated EA.hy926 cells. Accordingly, endothelial cells were exposed during 18 hours with different concentrations of TNF- $\alpha(50-500 \mathrm{ng} / \mathrm{mL})$ and levels of the pro-inflammatory marker IL-6 and cell viability were evaluated. Figure 4A shows that rising concentrations of TNF- $\alpha$ induced a dose-dependent increase of IL-6 levels in the culture medium. Furthermore, none of the tested doses caused cell injury in EA.hy926 cells (Figure 4B). Since the concentration of $50 \mathrm{ng} / \mathrm{mL}$ of TNF- $\alpha$ was the lowest dose that induces a significantly increase of IL-6, it was the concentration chosen for the following experiments.

Next, endothelial cells cultured in the presence or absence of microbial flavanol-derived metabolites DHPAA, DHBA and HPPA $(10 \mu \mathrm{M})$ and the MIX $(12 \mu \mathrm{M})$ during $6 \mathrm{~h}$ were further treated with $50 \mathrm{ng} / \mathrm{mL}$ of TNF- $\alpha$ from 18 hours and then IL-6 secretion was evaluated. As shown in Figure 4C, the IL-6 secretion induced by TNF- $\alpha$ was greatly prevented by the pretreatment of endothelial cells with different metabolites and the MIX. Interestingly, the MIX containing lower doses of these microbial-derived flavanol metabolites $(4 \mu \mathrm{M}$ of DHPAA +4 $\mu \mathrm{M}$ of DHBA $+4 \mu \mathrm{M}$ of HPPA) was the most effective to prevent TNF- $\alpha$ induced inflammation. According to these results, we selected the MIX for the subsequent experiments.

\subsection{Cocoa flavanol metabolites protect endothelial cells against TNFa-mediated monocyte adhesion}


To address whether the MIX treatment modulates cytokine expression and monocyte adhesion in TNF- $\alpha$-stimulated EA.hy926 cells, protein levels of IL-6 and adhesion molecules such as ICAM-1 and VCAM-1 were also analysed. As shown in Figures 5A and 5B, treatment of endothelial cells with the MIX significantly decreased TNF- $\alpha$-induced IL-6 secretion and expression levels of IL-6, ICAM-1 and VCAM-1. The next step was to examine the effect of colonic metabolites on monocyte adhesion. As shown in Figure 5C, the incubation of endothelial cells with TNF- $\alpha(50 \mathrm{ng} / \mathrm{mL})$ for $18 \mathrm{~h}$ led to a significant increase in monocyte adhesion to endothelial cells. However, pre-treatment of cells with the MIX $(6 \mathrm{~h})$ prior to the addition of TNF- $\alpha$ significantly decreased TNF- $\alpha$-induced monocyte adhesion. These results were confirmed under fluorescent microscopy, as shown in Figure 5D. These outcomes strongly indicate that colonic metabolites totally prevent the expression of cell adhesion molecules and monocyte adhesiveness in TNF- $\alpha$-treated endothelial cells.

\subsection{Cocoa flavanol metabolites reduce p-p65 NF-кB, COX-2 and iNOs levels in TNF- $\alpha$ treated endothelial cells}

Next, to determine whether the flavanol colonic metabolites had an impact on the transcriptional regulation of pro-inflammatory pathways, levels of p-p65, which is responsible for $\mathrm{NF}-\kappa \mathrm{B}$ activation, and the inflammatory enzymes $\mathrm{COX}-2$ and iNOS were determined in TNF- $\alpha$ treated endothelial cells. To this end, EA.hy962 cells were pre-treated or not with the MIX for $6 \mathrm{~h}$ and further stimulated with TNF- $\alpha(50 \mathrm{ng} / \mathrm{mL})$ during $18 \mathrm{~h}$; then, levels of p-p65 NF- $\mathrm{B}, \mathrm{COX}-2$ and iNOs were evaluated by Western blot. As shown in Figure 6, levels of p-p65, COX-2 and iNOS were significantly enhanced in TNF- $\alpha-$ stimulated endothelial cells. However, this pro-inflammatory effect was totally prevented in TNF- $\alpha$-stimulated cells that were pre-treated with the MIX. Altogether, these results indicate 
that a MIX of colonic flavanols-derived metabolites significantly reduce endothelial vascular inflammation in TNF- $\alpha$-stimulated cells. 


\section{Discussion}

Oxidative stress and inflammation are the major contributing factors for the development of vascular dysfunction and cardiovascular disease in T2D (Oguntibeju, 2019). We have previously showen that cocoa intake has the potential to improve vascular health in a well-characterized animal model of T2D (Alvarez-Cilleros et al., 2019). This protective effect was due in part to its ability to improve vascular function and to prevent oxidative stress and aortic stiffening and remodelling. Herein, we show for the first time that cocoa flavonoids can also avoid vascular inflammation in Zucker diabetic rats and in TNF- $\alpha$ stimulated endothelial cells, further contributing to its vascular protective activity in diabetes.

In diabetes induced oxidative stress leads to increased levels of pro-inflammatory cytokines in vascular tissues and to upregulate cell adhesion molecules such as ICAM-1 and VCAM-1, which are involved in monocyte-endothelial adhesion (La Sala et al., 2019). The recruitment of monocytes to the arterial wall and their differentiation into macrophages initiate chronic inflammation and the development of a large proportion of cardiovascular diseases. Evidences from previous epidemiological and clinical studies suggest that cocoa intake has favourable effects on a variety of cardiometabolic parameters, representing a promising bioactive food in the prevention of cardiovascular diseases (Jafari Azad et al.; Lin et al., 2016; Grassi et al., 2015) More importantly, regular consumption of flavanol-rich cocoa has been related to decreased cellular and humoral inflammation markers in patients suffering from $\mathrm{T} 2 \mathrm{D}$, suggesting a potential role of cocoa to avoid vascular inflammation in diabetes (Ellinger \& Stehle, 2016). In line with these reports, here we found that cocoa intake was able to prevent the low grade of inflammation in Zucker diabetic rats by reducing the level of inflammatory mediators such as IL-6, VCAM-1 and ICAM-1 in aortic tissues. 
These findings strongly indicate that cocoa may down-regulate the expression of vascular adhesion molecules in the vascular wall of diabetic animals and in consequence may prevent the inflammatory processes associated with endothelial monocyte adhesion.

The nuclear transcription factor NF- $\mathrm{kB}$ is considered to be the major regulator involved in the expressions of cellular adhesion molecules and migration of leukocytes through the endothelium (Suryavanshi \& Kulkarni, 2017). Furthermore, the NF-кB signalling system also plays a pivotal role in the expression of pro-inflammatory enzymes such as iNOS and COX-2 that have been involved in hyperglycaemia-mediated endothelial apoptosis and the occurrence of diabetes-related complications (Zhang et al., 2014). In this regard, flavonoids acting as NF- $\mathrm{KB}$ inhibitors have been shown to modulate the expression of pro-inflammatory genes leading to the attenuation of the inflammatory responses underlying in various pathologies (Choy et al., 2019). In particular, the ability of cocoa to modulate NF- $\mathrm{kB}$ actions has been previously demonstrated in different tissues such as colon (Rodríguez-Ramiro et al, 2013), adipose tissue (Gu et al., 2014) myocardial tissue (Ahmed et al., 2020) and in peripheral blood mononuclear cells (Vázquez-Agell et al., 2013). According to that, in this study we found that cocoa intake prevents the phosphorylation of NF- $\mathrm{KB}$ and the upregulation of iNOS in the aorta of ZDF rats, supporting thus the antiinflammatory effect of cocoa in diabetes. Mechanistically, it has been shown that reactive oxygen species (ROS) play an essential role in the modulation of NF- $\mathrm{kB}$ by the activation of the mitogen-activated protein kinases (MAPKs) (La Sala et al., 2019). Interestingly, we have previously found that cocoa intake significantly prevented ROS generation and the consequent activation of stress signalling pathways in the aorta of ZDF rats (AlvarezCilleros et al., 2019). Therefore, we could suggest that modification of the cellular redox status by cocoa may contribute to control the activation of NF- $\mathrm{kB}$ and thus the inflammatory 
cellular response to oxidative stress induced by diabetes. Overall, these data strongly demonstrate that cocoa supplementation can protect against diabetic vascular inflammation by preventing NF- $\kappa \mathrm{B}$ phosphorylation, which in turn decreases ICAM-1, VCAM-1 and iNOS expression in aortic tissues.

In order to verify whether colonic metabolites from cocoa flavanols could be in part responsible for the vascular benefits observed in diabetic animals, we next investigate their potential anti-inflammatory effect in vitro, using TNF- $\alpha$-stimulated endothelial cells. Recent published data evidence that health benefits of flavonoids can largely result from the biological activity of their microbial-derived metabolites (Ruotolo et al., 2020; Del Bo et al., 2019; Bharat et al., 2018). Indeed, most of ingested flavonoids have limited bioavailability whereas their gut-derived metabolites are found in the circulatory system at higher concentrations relative to the parent compounds (Kay et al., 2017). Therefore, the use of flavanol colonic metabolites in vitro may reproduce physiological conditions more precisely than the use of native forms (Mena \& Del Rio, 2018). Besides, we have used realistic doses $(1-10 \mu \mathrm{M})$ since phenolic acids could be detected in plasma at low $\mu \mathrm{M}$ concentrations after the intake of foodstuff containing flavanols (Urpi-Sarda et al., 2009). In concordance with this, we have recently demonstrated that a mix of microbial-derived metabolites from flavanols at physiological concentrations stimulate nitric oxide production in human endothelial cells and protect them against oxidative stress-induced toxicity and endothelial dysfunction (Álvarez-Cilleros et al., 2018). In the present work, we found that the same mix of gut-derived metabolites was also able to protect endothelial cells against TNF- $\alpha$-induced inflammation. More importantly, this effect was higher than the observed with the single metabolites alone, suggesting additive or synergistic effects. Similar results have been described in previous studies showing that the combination of common gut microbial 
metabolites of dietary anthocyanins at low micromolar concentrations induced greater antiinflammatory effects in human THP-1 monocytes than their individual constituents isolated (Di Gesso et al., 2015). Overall, these findings indicate that microbial-derived metabolites from flavanols may have an important role in preventing the low grade of inflammation found in the aorta of Zucker diabetic rats.

Few studies have investigated the effects of microbial derived metabolites from flavonoids on adhesion molecules and on monocyte adhesion in endothelial cells (Tang et al., 2019, Krga et al., 2016, Amin et al., 2015,). For example, Krga et al. (2016) revealed that isolated anthocyanidins-derived gut metabolites such as protocatechuic, vanillic, ferulic and hippuric acid at realistic concentrations decreased the adhesion of monocytes to human endothelial cells. These preventive effects were also confirmed when derived metabolites were used in combination (Tang et al., 2019, Krga et al., 2016). In the present study, we demonstrate for the first time that a mix of bioavailable flavanol-derived metabolites, at physiologically relevant concentrations, strongly prevents THP-1 monocyte-endothelial adhesion in TNF- $\alpha$-treated endothelial cells. Moreover, this effect was associated with a significantly reduction in the protein expression of VCAM-1 and ICAM-1 and in the phosphorylation of NF- $\kappa \mathrm{B}$. These results are in concordance with a previous study reporting that a metabolite derived from flavanols (5-dihydroxyphenyl-valerolactone) downregulated levels of VCAM-1 and MCP-1 in human endothelial cells and attenuated THP-1 monocyteendothelial adhesion (Lee et al., 2017). Likewise, increased levels of the inflammatory enzymes iNOS and COX-2 induced by TNF- $\alpha$ were totally prevented by the mix of flavanol-derived gut metabolites. Altogether, these findings strongly support the antiinflammatory activity of microbial-derived metabolites from flavanols and provide new evidences supporting their significant role in the specific biological effects of flavanols. 
It is interesting to note that cocoa comprise other bioactive compounds, mainly the methylxanthine theobromine, that could also be participating in the beneficial effects of cocoa on vascular function. Indeed, it has been shown that theobromine can be the responsible of immunoregulatory effects of cocoa (Camps-Bossacoma et al., 2018). More recently, theobromine has also been associated with some of the effects of cocoa intake on glucose and lipid metabolisms (Camps-Bossacoma et al., 2019). Further studies will clarify whether the protective effect of cocoa on vascular function can also be partly ascribed to theobromine and/or to a possible synergistic activity among theobromine and cocoa flavanols.

In summary, this study is the first work demonstrating that dietary cocoa supplementation may have an important effect in preventing the progression of inflammation in diabetes by reducing NF- $\kappa$ B phosphorylation and levels of ICAM-1, VCAM-1 and iNOS in aortic tissues. Moreover, the experiments with endothelial cells further confirm that flavanol-derived colonic metabolites effectively down-regulate the levels of p-p65-NF- $\kappa$ B, as well as ICAM-1 and VCAM-1 cell adhesion molecules, preventing thus monocyte-endothelial adhesion induced by TNF- $\alpha$. Notably, these novel data provide evidences on the anti-inflammatory vascular activity of flavanol-derived colonic metabolites and their significant role on the preventive effect of cocoa in diabetic vascular diseases. 


\section{Conflict of interest}

The authors declare that there are no conflicts of interest.

\section{Acknowledgments}

This work was supported by the grant AGL2015-67087-R (MINECO/FEDER, UE) and RTI2018-095059-B-I00 (MCIU/AEI/FEDER, UE). D. Álvarez-Cilleros is a fellow of the FPI predoctoral program (MINECO, BES-2016-076721).

\section{Author contributions}

D.A-C.: Investigation, Data curation, Visualization, Formal analysis. M.E.L-O.: Investigation, Data curation, Visualization, Formal analysis. S.R.: Methodology, Investigation, Supervision, Writing - review \& editing, Funding acquisition. M,A.M.: Conceptualization, Methodology, Investigation, Writing - original draft, Writing - review \& editing, Funding acquisition. 


\section{References}

Actis-Goretta, L., Leveques, A., Giuffrida, F., Romanov- Michailidis, F., Viton, F., Barron, D., Duenas-Paton, M., Gonzalez-Manzano, S., Santos-Buelga, C., Williamson, G., Dionisi, F., 2012. Elucidation of (-)-epicatechin metabolites after ingestion of chocolate by healthy humans. Free Radical Biol. Med. 53,787-795

Ahmed, S.; Ahmed, N.; Rungatscher, A.; Linardi, D.; Kulsoom, B.; Innamorati, G.; Meo, S.A.; Gebrie, M.A.; Mani, R.; Merigo, F.; Guzzo, F.; Faggian, G., 2020 Cocoa Flavonoids Reduce Inflammation and Oxidative Stress in a Myocardial IschemiaReperfusion Experimental Model. Antioxidants. 9(2), 167.

Álvarez-Cilleros, D.; López-Oliva, M.E.; Morales-Cano, D.; Barreira, B.; PérezVizcaíno, F.; Goya, L.; Ramos, S.; Martín, M.A., 2019. Dietary Cocoa Prevents Aortic Remodelling and Vascular Oxidative Stress in Diabetic Rats. Mol. Nutr. Food Res. 63(18), 1900044

Àlvarez-Cilleros, D.; Ramos, S.; Goya, L.; Martín, M.A., 2018. Colonic metabolites from flavanols stimulate nitric oxide production in human endothelial cells and protect against oxidative stress-induced toxicity and endothelial dysfunction. Food Chem. Toxicol. $115,88-97$

Amin, H.P.; Czank, C.; Raheem, S.; Zhang, Q.; Botting, N.P.; Cassidy, A.; Kay, C.D., 2015. Anthocyanins and their physiologically relevant metabolites alter the expression of IL-6 and VCAM-1 in CD40L and oxidised LDL challenged vascular endothelial cells. Mol. Nutr. Food Res. 59(6), 1096-106

Bharat, D.; Cavalcanti, R.R.M.; Petersen, C.; Begaye, N.; Cutler, B.R.; Costa, M.M.A.; Ramos, R.K.L.G.; Ferreira, M.R.; Li, Y.; Bharath, L.P.; Toolson, E.; Sebahar, P.; Looper, R.E.; Jalili, T.; Rajasekaran, N.S.; Jia, Z.; Symons, J.D.; Babu, P.V.A., 2018. 
Blueberry Metabolites Attenuate Lipotoxicity-Induced Endothelial Dysfunction. Mol. Nutr. Food Res. 2018, 62(2). doi: 10.1002/mnfr.201700601

Camps-Bossacoma, M.; Pérez-Cano, F.J.; Franch, À.; Castell, M., 2018. Theobromine Is Responsible for the Effects of Cocoa on the Antibody Immune Status of Rats. J Nutr. 148(3), 464-471

Camps-Bossacoma, M.; Garcia-Aloy, M.: Saldaña-Ruiz, S.; Cambras, T.; GonzálezDomínguez, R.; Franch, A.; Pérez-Cano, F.J.; Andres-Lacueva, C.; Castell, M., 2019. Role of Theobromine in Cocoa's Metabolic Properties in Healthy Rats. J Agric Food Chem. 67(13), 3605-3614.

Caro-Ordieres, T.; Marín-Royo, G.; Opazo-Ríos, L.; Jiménez-Castilla, L.; Moreno, J.A.; Gómez-Guerrero, C.; Egido, J., 2020. The Coming Age of Flavonoids in the Treatment of Diabetic Complications. J. Clin. Med. 9(2), 346

Choy, K.W.; Murugan, D.; Leong, X-F.; Abas, R.; Alias, A.; Mustafa, M.R., 2019. Flavonoids as Natural Anti- Inflammatory Agents Targeting Nuclear Factor-Kappa B (NFkB) Signaling in Cardiovascular Diseases: A Mini Review. Front. Pharmacol. 10, 1295.

Del Bo, C.; Marino, M.; Riso, P.; Møller, P.; Porrini, M., 2019. Anthocyanins and metabolites resolve TNF- $\alpha$-mediated production of E-selectin and adhesion of monocytes to endothelial cells. Chem. Biol. Interact. 300, 49-55

Di Gesso, J.L.; Kerr, J.S.; Zhang, Q.; Raheem, S.; Yalamanchili, S.K.; O'Hagan, D.; Kay, C.D.; O'Connell, M.A., 2015. Flavonoid metabolites reduce necrosis factor- $\alpha$ secretion to a greater extent than their precursor compounds in human monocytes. Mol. Nutr. Food Res. 59(6), 1143-1154

Ellinger, S.; Stehle, P., 2016. Impact of Cocoa Consumption on Inflammation Processes-A Critical Review of Randomized Controlled Trials. Nutrients. 8(6), 321 
Fallah, A.A.; Sarmast, E.; Fatehi, P.; Jafari, T., 2020 Impact of dietary anthocyanins on systemic and vascular inflammation: Systematic review and meta-analysis on randomised clinical trials. Food Chem. Toxicol. 135, 110922.

Ferri, C.; Desideri, G.; Ferri, L.; Proietti, I.; Di Agostino, S.; Martella, L; Mai, F,: Di Giosia, P.; Grassi, D., 2015. Cocoa, blood pressure, and cardiovascular health. J. Agric. Food Chem. 63(45), 9901-9909.

García-Carro, C.; Vergara, A.; Agraz, I.; Jacobs-Cachá, C.; Espinel, E.; Seron, D.; Soler, M.J., 2019. The New Era for Reno-Cardiovascular Treatment in Type 2 Diabetes. J. Clin. Med. 8 (6), 864-880.

Grassi, D.; Desideri, G.; Necozione, S; Giosia, P.; Barnabei, R.; Allegaert, L.; Bernaert, H.; Ferri, C., 2015. Cocoa consumption dose-dependently improves flow-mediated dilation and arterial stiffness decreasing blood pressure in healthy individuals. J. Hypertens. 33(2), 294-303.

Gu, Y.; Yu, S.; Park, J.Y.; Harvatine, K.; Lambert, J.D. 2014. Dietary cocoa reduces metabolic endotoxemia and adipose tissue inflammation in high-fat fed mice. J. Nutr. Biochem. 25(4), 439-445.

Ha, S.J., Lee, J., Song, K-M., Kim, Y.H., Lee, N.H., Kim, Y-E., Jung, S.K., 2018. Ultrasonicated Lespedeza cuneata extract prevents TNF- $\alpha$-induced early atherosclerosis in vitro and in vivo. Food Funct. 9, 2090-2101.

Hussain, T.; Murtaza, G.; Yang, H.; Kalhoro, M.S.; Kalhoro, D.H., 2020. Exploiting anti-Inflammation effects of flavonoids in chronic inflammatory diseases. Curr. Pharm. Des. 26(22), 2610-2619.

Jafari Azad, B.; Daneshzad, E.; Meysamie, A.P.; Koohdani, F., 2020. Chronic and acute effects of cocoa products intake on arterial stiffness and platelet count and function: A 
systematic review and dose-response Meta-analysis of randomized clinical trials. Crit, Rev. Food Sci. Nutr. 1-23. doi:10.1080/10408398.2020.1733484

Kay, C. D.; Pereira-Caro, G.; Ludwig, I. A.; Clifford, M. N.; \& Crozier, A., 2017. Anthocyanins and flavanones are more bioavailable than previously perceived: A review of recent evidence. Annu. Rev. Food Sci. Technol. 28(8), 155-180.

Krga, I.; Monfoulet, L-E.; Konic-Ristic, A.; Mercier, S.; Glibetic, M.; Morand, C.; Milenkovic, D., 2016. Anthocyanins and their gut metabolites reduce the adhesion of monocyte to $\mathrm{TNFa}$-activated endothelial cells at physiologically relevant concentrations. Arch. Biochem. Biophys. 599(1), 51-9.

Lapuente, M.; Estruch, R; Shahbaz, M.; Casas, R.; 2019. Relation of Fruits and Vegetables with Major Cardiometabolic Risk Factors, Markers of Oxidation, and Inflammation. Nutrients. 11(10), 2381.

La Sala, L.; Prattichizzo, F.; Ceriello, A., 2019. The link between diabetes and atherosclerosis. Eur. J. Prev. Cardiol. 26(2), 15-24.

Lee, C.C.; Kim, J.H.: Kim, J.S.; Oh, Y.S.; Han, S.M.; Park, J.H.Y.; Lee, K.W.; Lee, C.Y., 2017. 5-(3,4-Dihydroxyphenyl-valerolactone), a Major Microbial Metabolite of Proanthocyanidin, Attenuates THP-1 Monocyte-Endothelial Adhesion. Int. J. Mol. Sci. 18(7), 1363

Lin, X.; Zhang, I.; Li, A.; Manson, J.E.; Sesso, H.D.; Wang, L.; Liu, S., 2016. Cocoa Flavanol Intake and Biomarkers for Cardiometabolic Health: A Systematic Review and Meta-Analysis of Randomized Controlled Trials. J. Nutr. 146(11), 2325-33.

Maleki, S,J.; Crespo, J.F.; Cabanillas, B., 2019 Anti-inflammatory effects of flavonoids. Food Chem. 299, 125124 
Martin, M.A.; Ramos, S., 2017. Health beneficial effects of cocoa phenolic compounds: a mini-review. Curr. Opin. Food Sci. 14:20-25

Mayorga-Gross, A.L; Esquivel, P., 2019. Impact of Cocoa Products Intake on Plasma and Urine Metabolites: A Review of Targeted and Non-Targeted Studies in Humans. Nutrients. 11(5), 1163

Mena, P.; Del Rio, D. 2018. Gold Standards for Realistic (Poly)phenol Research. J Agric Food Chem. 66(31), 8221-8223.

Oguntibeju, O.O., 2019. Type 2 diabetes mellitus, oxidative stress and inflammation: examining the links. Int. J. Physiol. Pathophysiol. Pharmacol. 11(3):45-63.

Ottaviani, J.I., Borges, G., Momma, T.Y., Spencer, J.P.E., Keen, C.L., Crozier, A., Schroeter, H., 2016. The metabolome of [2-14C](-)-epicatechin in humans: implications for the assessment of efficacy, safety, and mechanisms of action of polyphenolic bioactives. Sci. Rep. 6, 29034.

Rodríguez-Ramiro, I.; Ramos, S.; López-Oliva, E.; Agis-Torres, A.; Bravo, L.; Goya, L.; Martin, M.A., 2013. Cocoa polyphenols prevent inflammation in the colon of azoxymethane-treated rats and in TNF-a-stimulated Caco-2 cells. Br. J. Nutr. 110(2), 206215

Ruotolo, R.; Minato, I.; La Vitola, P.; Artioli, L.; Curti, C.; Franceschi, V.; Brindani, N.; Amidani, D.; Colombo, L.; Salmona, M.; Forloni, G.; Donofrio, G.; Balducci, C.; Del Rio, D.; Ottonello, S., 2020. Flavonoid-Derived Human Phenyl- $\gamma$-Valerolactone Metabolites Selectively Detoxify Amyloid- $\beta$ Oligomers and Prevent Memory Impairment in a Mouse Model of Alzheimer's Disease. Mol Nutr Food Res. 64(5), e1900890. 
Santhakumar, A.B.; Battino, M.; Alvarez-Suarez, J.M., 2018. Dietary polyphenols: Structures, bioavailability and protective effects against atherosclerosis. Food Chem. Toxicol. 113, 49-65.

Shah, M.S.; Brownlee, M., 2016. Molecular and Cellular Mechanisms of Cardiovascular Disorders in Diabetes. Circ. Res. 118, 1808-1829

Suryavanshi, S.V.; Kulkarni, Y.A., 2017. NF-к $\beta$ : A Potential Target in the Management of Vascular Complications of Diabetes. Front. Pharmacol. 8, 798

Tang, J.S.; Bozonet, S.M.; McKenzie, J.L.; Anderson, R.F.; Melton L.D.; Vissers, M.C.M., 2019. Physiological Concentrations of Blueberry-Derived Phenolic Acids Reduce Monocyte Adhesion to Human Endothelial Cells. Mol. Nutr. Food Res. 63, 1900478

Toma, L.; Sanda, G.M.; Niculescu, L.S.; Deleanu, M.; Sima, A.V.; Stancu, C.S. 2020. Phenolic Compounds Exerting Lipid-Regulatory, Anti-Inflammatory and Epigenetic Effects as Complementary Treatments in Cardiovascular Diseases. Biomolecules 10(4), 641. Urpi-Sarda, M., Monagas, M., Khan, N., Llorach, R., Lamuela-Raventos, R.M., Jauregui, O., Estruch, R., Izquierdo-Pulido, M., Andres-Lacueva, C., 2009. Targeted metabolic profiling of phenolics in urine and plasma after regular consumption of cocoa by liquid chromatography-tandem mass spectrometry. J. Chromatogr., A 1216, 7258-7267.

Vázquez-Agell, M.; Urpi-Sarda, M.; Sacanella, E.; Camino-López, S.; Chiva-Blanch, G.; Llorente-Cortés, V.; Tobias, E.; Roura, E.; Andres-Lacueva, C.; Lamuela-Raventós, R.M.: Badimon, L.; Estruch, R., 2013. Cocoa consumption reduces NF-kB activation in peripheral blood mononuclear cells in humans. Nutr. Metab. Cardiovasc. Dis. 23(3), 257263. 
Xia, F.; Wang, C.; Jin, Y.; Liu, Q.; Meng, Q.; Liu, K.; Sun, H., 2014. Luteolin protects HUVECs from TNF-alpha-induced oxidative stress and inflammation via its effects on the Nox4/ROS-NF-kappaB and MAPK pathways. J. Atheroscler. Thromb. 21:768-783.

Zhang, X.; Fu, Y.; Xu, X.; Li, M.; Du, L.; Han, Y.; Ge, Y., 2014. PERK pathway are involved in NO-induced apoptosis in endothelial cells cocultured with RPE under high glucose conditions. Nitric Oxide. 40(31), 10-16 


\section{Legends to Figures}

Figure 1.- Effect of cocoa diet on vascular inflammation in Zucker lean (ZL), Zucker diabetic rats fed control diet (ZDF-C) and Zucker diabetic rats fed cocoa diet (ZDFCo). (A) Representative photographs for immunohistochemical staining of IL-6 (brownstained) and immunoreactive score (scale bar $10 \mu \mathrm{m}$ ) in arterial tissues. (B) Representative photographs for immunohistochemical staining of TNF- $\alpha$ (brown-stained) and immunoreactive score (scale bar $10 \mu \mathrm{m}$ ) in arterial tissues. (C) Levels of TNF- $\alpha$ and IL-6 in plasma. Values are expressed as mean \pm SD $(n=6-8)$. Means sharing the same letter are not significantly different from each other $(\mathrm{P}<0.05)$.

Figure 2.- Effect of a cocoa diet on ICAM-1, VCAM-1 and MCP-1 levels in arteries from Zucker lean (ZL), Zucker diabetic rats fed control diet (ZDF-C) and Zucker diabetic rats fed cocoa diet (ZDF-Co). Representative photographs for immunohistochemical staining of ICAM-1 (A), VCAM-1 (B) and MCP-1 (C) (brownstained) and immunoreactive score (scale bar $10 \mu \mathrm{m}$ ) in arterial tissues. Means sharing the same letter are not significantly different from each other $(\mathrm{P}<0.05)$.

Figure 3.- Effect of a cocoa diet on p-p65 NF-кB, COX-2 and iNOS levels in arteries from Zucker lean (ZL), Zucker diabetic rats fed control diet (ZDF-C) and Zucker diabetic rats fed cocoa diet (ZDF-Co). Representative photographs for immunohistochemical staining of p-p65 (A), iNOS (B) and COX-2 (C) (brown-stained) and immunoreactive score (scale bar $10 \mu \mathrm{m}$ ) in arterial tissues. Values are expressed as mean \pm 
SD $(n=6-8)$. Means sharing the same letter are not significantly different from each other $(\mathrm{P}<0.05)$.

Figure 4.- Effect of colonic flavanol metabolites on TNF- $\alpha$-induced inflammation in endothelial cells. EA.hy926 cells were treated during $18 \mathrm{~h}$ with different concentrations of TNF- $\alpha$ (50-500 ng) and IL-6 secretion (A) and cell viability (B) were determined. EA.hy926 cells cultured with DHPAA $(10 \mu \mathrm{M})$, DHBA $(10 \mu \mathrm{M})$, HPPA $(10 \mu \mathrm{M})$ or the MIX $(12 \mu \mathrm{M})$ for $6 \mathrm{~h}$ were further treated with $50 \mathrm{ng} / \mathrm{mL}$ of TNF- $\alpha$ from 18 hours and IL-6 secretion was evaluated (C). Data represent means \pm SD of 8-10 samples per condition. Different letters denote statistically significant differences, $\mathrm{P}<0.05$.

Figure 5.- Effect of colonic flavanol metabolites on TNF- $\alpha$-induced monocyte adhesion in endothelial cells. (A) EA.hy926 cells cultured with or without MIX $(12 \mu \mathrm{M})$ for $6 \mathrm{~h}$ were further treated with TNF- $\alpha(50 \mathrm{ng} / \mathrm{mL})$ for $18 \mathrm{~h}$ and IL-6 secretion was determined. (B) Endothelial cells cultured with or without MIX $(12 \mu \mathrm{M})$ for $6 \mathrm{~h}$ and further treated with TNF- $\alpha$ (50 $\mathrm{ng} / \mathrm{mL})$ for $18 \mathrm{~h}$ were subjected to Western blot analysis using antibodies to IL-6, ICAM-1 and VCAM-1. Bands are representative of four to six experiments. Normalization of Western blots was ensured by $\beta$-actin. Graphic represents the percentage values of IL-6, ICAM-1 and VCAM-1 relative to the control condition (mean \pm SD). (C) EA.hy926 cells cultured with or without MIX $(12 \mu \mathrm{M})$ for $6 \mathrm{~h}$ and with TNF- $\alpha(50 \mathrm{ng} / \mathrm{mL})$ for $18 \mathrm{~h}$ were incubated with fluorescently labelled THP-1 cells during $1 \mathrm{~h}$, and cell adhesion was measured by fluorescent plate reading. (D) Adherent THP-1 cells were observed using a fluorescent microscopy (scale bar $100 \mu \mathrm{m}$ ) as described in the Materials and methods. Fluorescence intensity was monitored at $485 \mathrm{~nm}$ excitation and $515 \mathrm{~nm}$ emissions. Data 
represent means \pm SD of 8-10 samples per condition. Different letters denote statistically significant differences, $\mathrm{P}<0.05$.

Figure 6.- Effect of colonic flavanol metabolites on p-p65 NF-кB, COX-2 and iNOS protein levels in TNF- $\alpha$-treated endothelial cells. EA.hy926 cells cultured with or without MIX $(12 \mu \mathrm{M})$ for $6 \mathrm{~h}$ and further treated with TNF- $\alpha(50 \mathrm{ng} / \mathrm{mL})$ for $18 \mathrm{~h}$ were subjected to Western blot analysis using antibodies to p-p65, COX-2 and iNOS. (A) Representative bands of four to six experiments. Normalization of Western blots was ensured by $\beta$-actin. (B) Percentage values of p-p65 relative to the control condition (means \pm SD). (C) Percentage values of COX-2 relative to the control condition (means \pm SD). (D) Percentage values of iNOS relative to the control condition (means \pm SD). Different letters denote statistically significant differences, $\mathrm{P}<0.05$. 
Table 1.- Composition of the experimental control and cocoa-rich diets

\begin{tabular}{|c|c|c|}
\hline Component (g/Kg dry weight) & Control & Cocoa \\
\hline Casein & 140 & 140 \\
\hline Dextrose & 155 & 155 \\
\hline Sucrose & 100 & 100 \\
\hline Fat & 40 & 40 \\
\hline t-BHQ (tert-butylhydroquinone) & 0.008 & 0.008 \\
\hline Mineral mix. & 35 & 35 \\
\hline Vitamin mix. & 10 & 10 \\
\hline L-Cys & 1.8 & 1.8 \\
\hline Cholin bitartrate & 2.5 & 2.5 \\
\hline Cellulose & 100 & 66 \\
\hline Starch & 415.7 & 349.7 \\
\hline Cocoa powder & - & 100 \\
\hline Energy (KJ/Kg diet) & 15048 & 15048 \\
\hline Total cocoa polyphenols $(\mathrm{g} / 100 \mathrm{~g})$ & - & 2.4 \\
\hline \multicolumn{3}{|l|}{ Cocoa flavonoids } \\
\hline Procyanidin B1 & - & 0.035 \\
\hline Catechin & - & 0.115 \\
\hline Procyanidin B2 & - & 0.132 \\
\hline Epicatechin & - & 0.382 \\
\hline Theobromine & - & 0.742 \\
\hline
\end{tabular}


Table 2.- Body weight and food and energy intake of rats fed with standard (ZL and ZDF) and cocoa-rich (ZDF-Co) diets. Data represent the means \pm SD of 6-8 animals. Means in a row without a common letter differ, $\mathrm{P}<0.05$.

\begin{tabular}{cccc} 
& ZL & ZDF-C & ZDF-Co \\
\cline { 2 - 4 } & $210 \pm 9^{\mathrm{a}}$ & $284 \pm 10^{\mathrm{b}}$ & $285 \pm 11^{\mathrm{b}}$ \\
Initial Body weight $(\mathrm{g})$ & $329 \pm 4^{\mathrm{a}}$ & $444 \pm 8^{\mathrm{b}}$ & $400 \pm 12^{\mathrm{c}}$ \\
Final Body weight $(\mathrm{g})$ & $123 \pm 9^{\mathrm{a}}$ & $180 \pm 10^{\mathrm{b}}$ & $121 \pm 9^{\mathrm{c}}$ \\
Body weight gain (g) & $1223 \pm 61^{\mathrm{a}}$ & $1839 \pm 74^{\mathrm{b}}$ & $1918 \pm 107^{\mathrm{b}}$ \\
$\begin{array}{c}\text { Total food intake (g in 10 } \\
\text { weeks) }\end{array}$ & & & \\
$\begin{array}{c}\text { Total energy intake (Kcal } \\
\text { in 10 weeks) }\end{array}$ & $4417 \pm 244^{\mathrm{a}}$ & $6643 \pm 289^{\mathrm{b}}$ & $6763 \pm 107^{\mathrm{b}}$ \\
$\begin{array}{c}\text { Food Efficiency (body } \\
\text { weight gain/total food } \\
\text { intake) }\end{array}$ & $0.10 \pm 0.01^{\mathrm{a}}$ & $0.09 \pm 0,02^{\mathrm{a}}$ & $0.06 \pm 0.01^{\mathrm{b}}$ \\
$\begin{array}{c}\text { Energy Efficiency (body } \\
\text { weight gain/total energy } \\
\text { intake) }\end{array}$ & $0.027 \pm 0.002^{\mathrm{a}}$ & $0.027 \pm 0.003^{\mathrm{a}}$ & $0.017 \pm 0.002^{\mathrm{b}}$ \\
\hline
\end{tabular}


Table 3.- Biological parameters of 20-week-old Zucker lean rats (ZL), Zucker diabetic fatty rats fed with control diet (ZDF-C) and Zucker diabetic fatty rats fed with cocoa diet (ZDFCo). Data represent the means \pm SD of 6-8 animals. Means in a row without a common letter differ, $\mathrm{P}<0.05$.

\begin{tabular}{cccc} 
& ZL & ZDF-C & ZDF-Co \\
\hline Glycaemia (mg/dL) & $86 \pm 9^{\mathrm{a}}$ & $238 \pm 7^{\mathrm{b}}$ & $118 \pm 11^{\mathrm{c}}$ \\
Insulinaemia (ng/mL) & $0.40 \pm 0,02^{\mathrm{a}}$ & $4.36 \pm 0.50^{\mathrm{b}}$ & $1.14 \pm 0.22^{\mathrm{c}}$ \\
HbA1c (\%) & $4.38 \pm 0.19^{\mathrm{a}}$ & $10.40 \pm 1.58^{\mathrm{b}}$ & $6.09 \pm 0.79^{\mathrm{c}}$ \\
HOMA-IR & $2.60 \pm 0.20^{\mathrm{a}}$ & $90.96 \pm 14.26^{\mathrm{b}}$ & $12.22 \pm 1.36^{\mathrm{c}}$ \\
TG (mmol/L) & $0.39 \pm 0.09^{\mathrm{a}}$ & $2.74 \pm 0.24^{\mathrm{b}}$ & $2.87 \pm 0.31^{\mathrm{b}}$ \\
HDL-Cho (mmol/L) & $2.27 \pm 0.22^{\mathrm{a}}$ & $2.85 \pm 0.37^{\mathrm{b}}$ & $3.08 \pm 0.32^{\mathrm{b}}$ \\
LDL-Cho (mmol/L) & $0.92 \pm 0.09^{\mathrm{a}}$ & $2.28 \pm 0.33^{\mathrm{b}}$ & $2.82 \pm 0.31^{\mathrm{c}}$ \\
\hline
\end{tabular}


Figure 1

A)
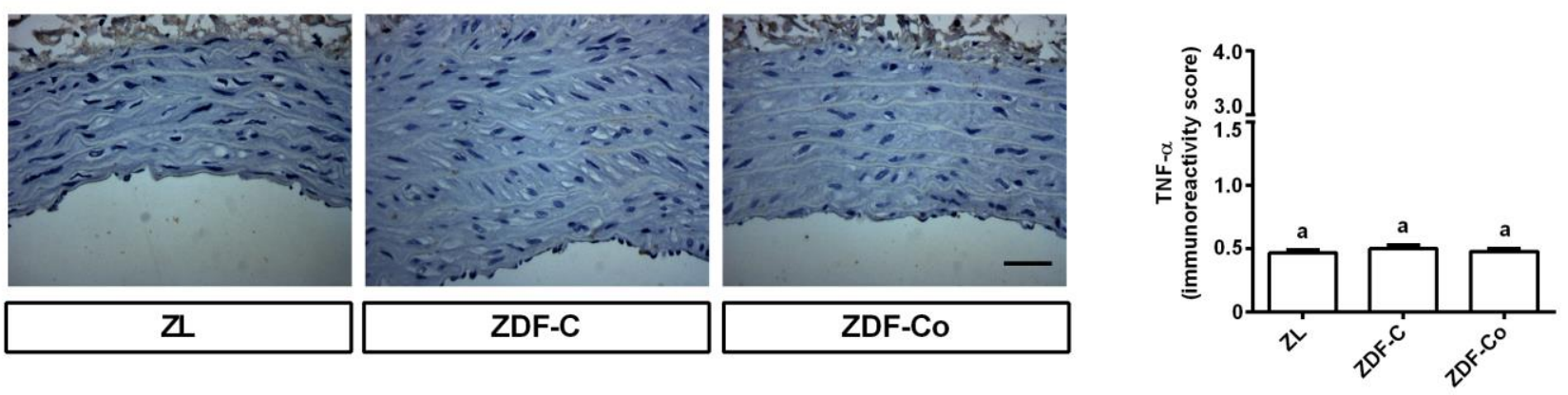

B)
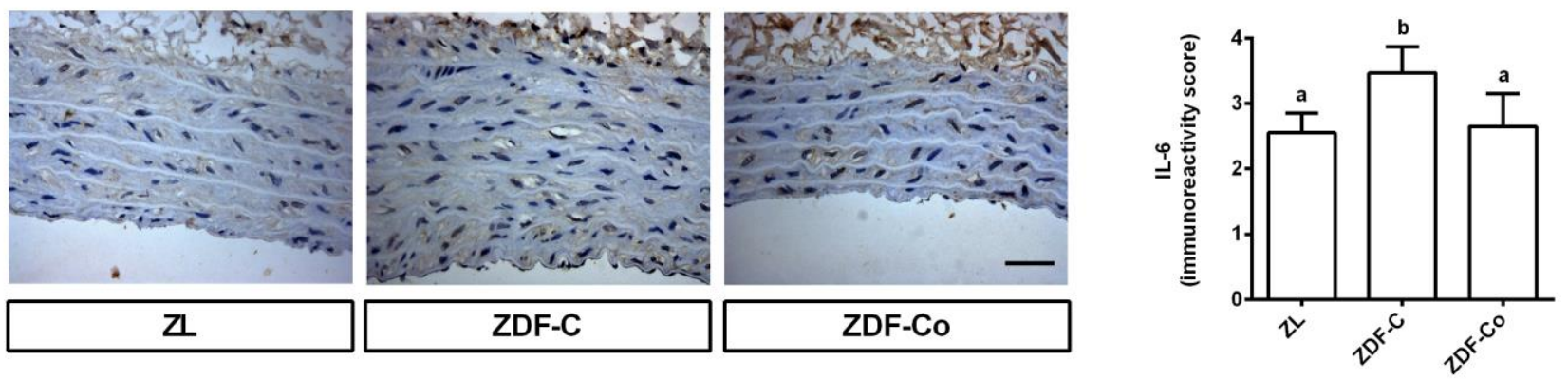

C)

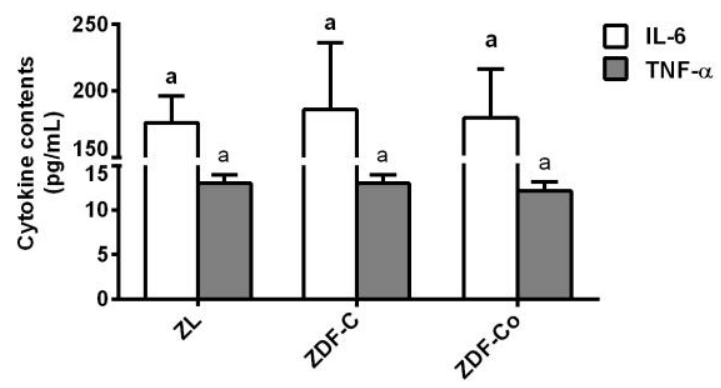


Figure 2

A)
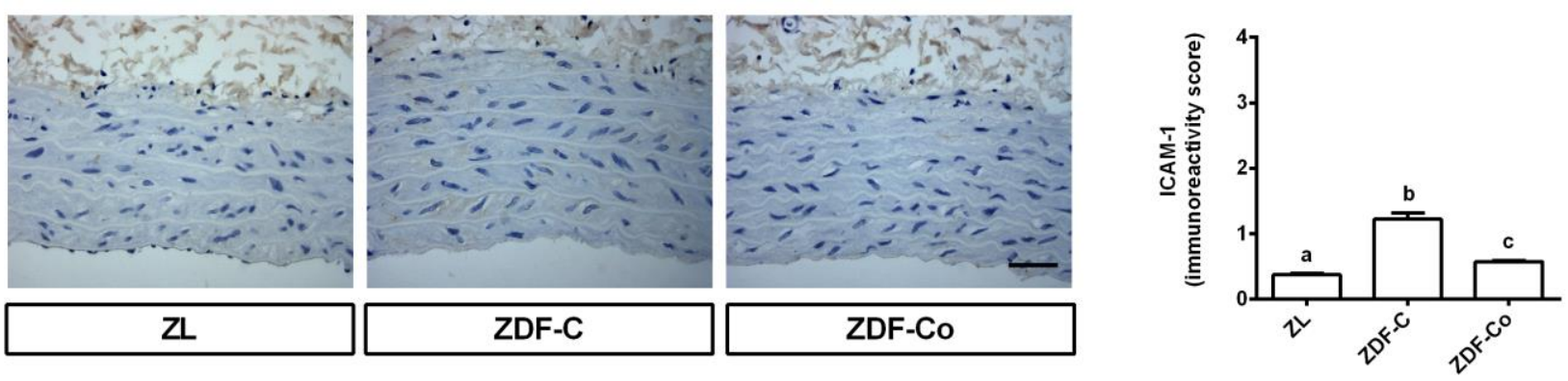

B)
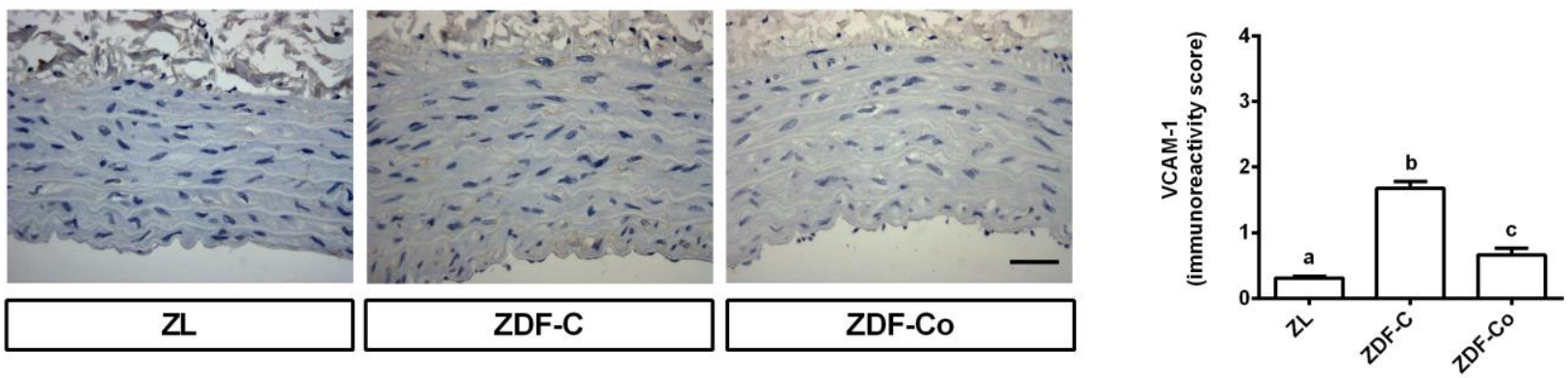

C)
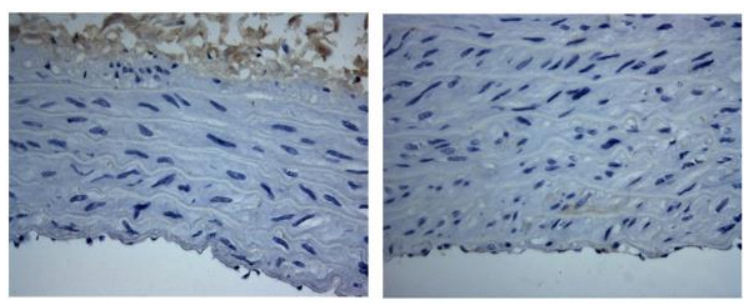

ZL

ZDF-C
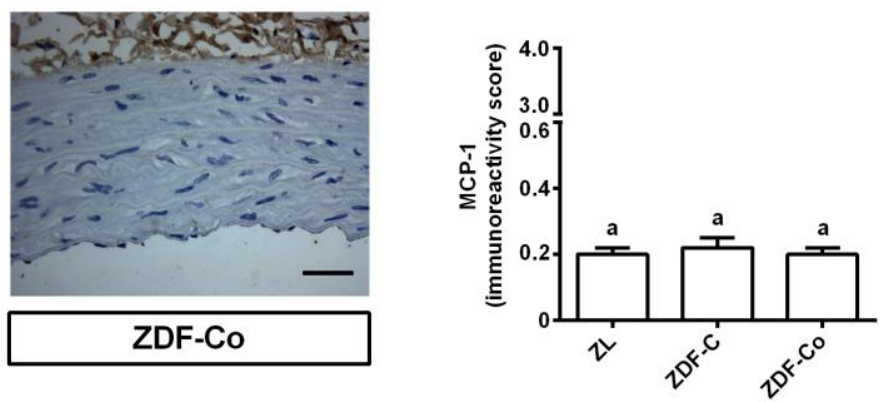
Figure 3

A)

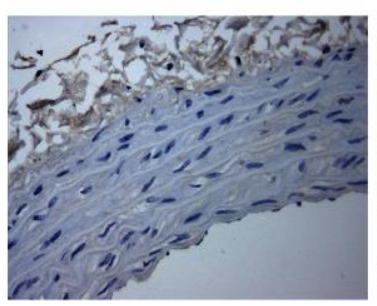

ZL

B)
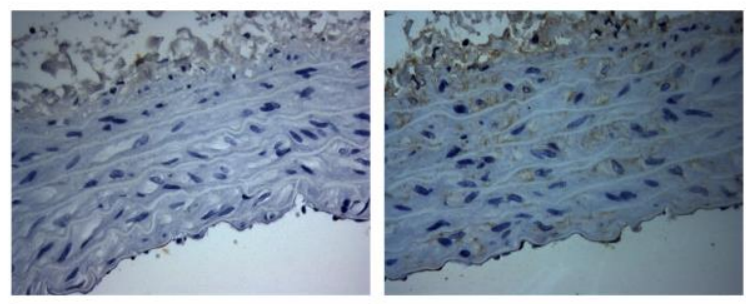

ZL
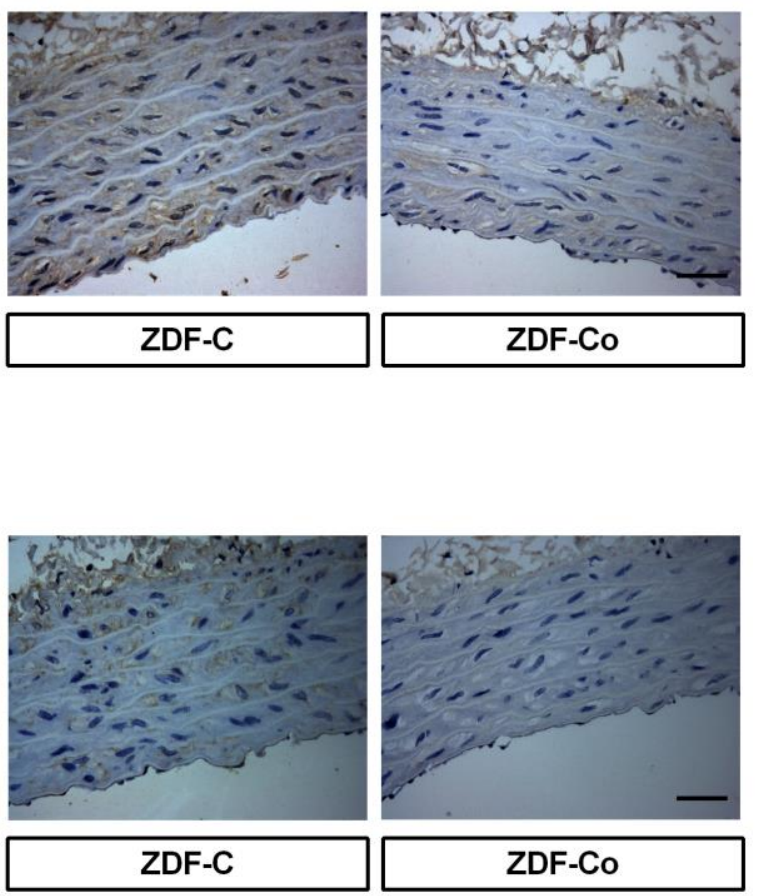

C)
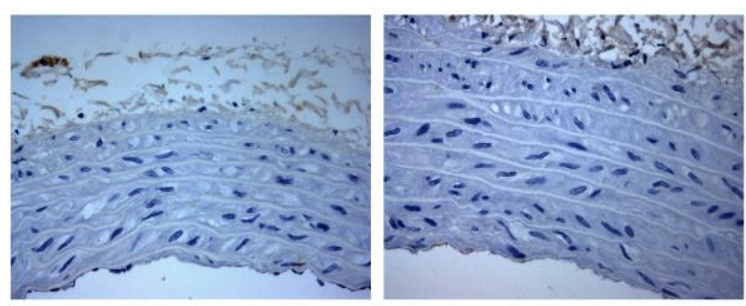

ZL

ZDF-C

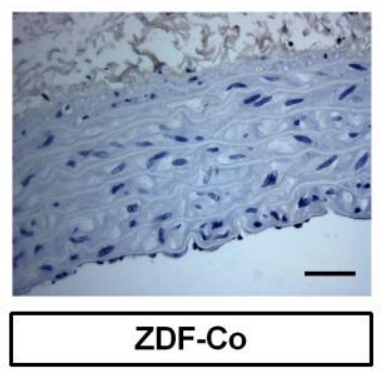

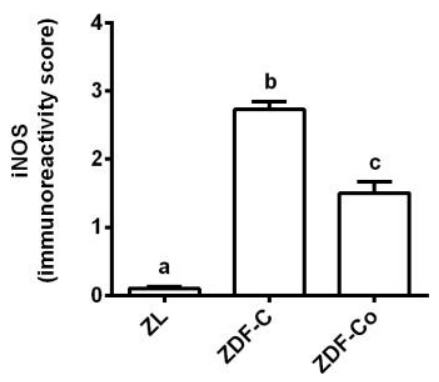

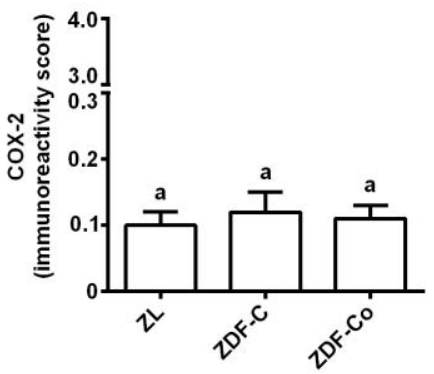


Figure 4

A)

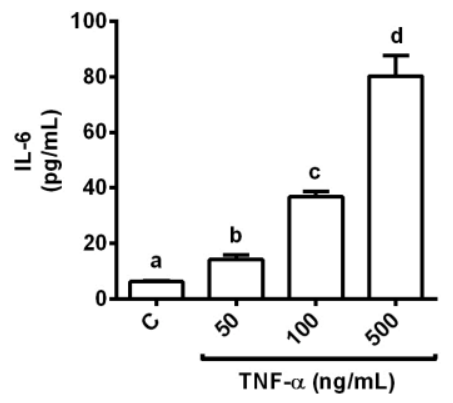

B)

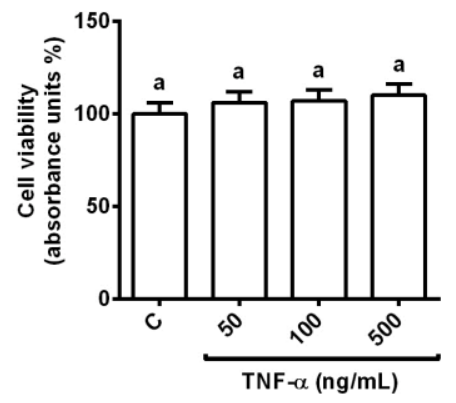

C)

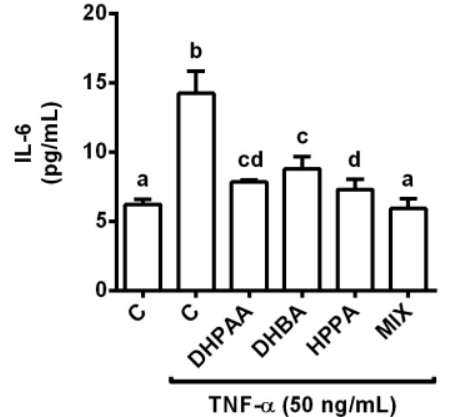


Figure 5

A)

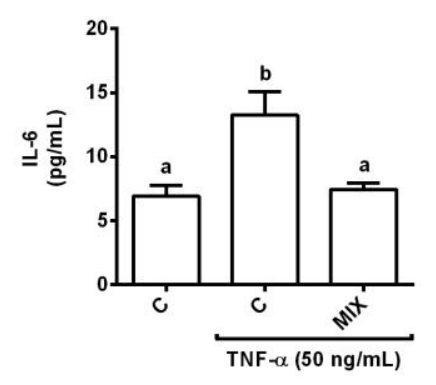

C)

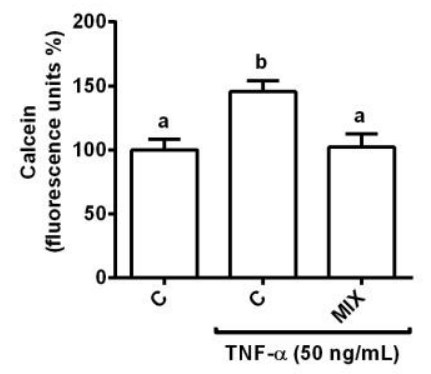

B)
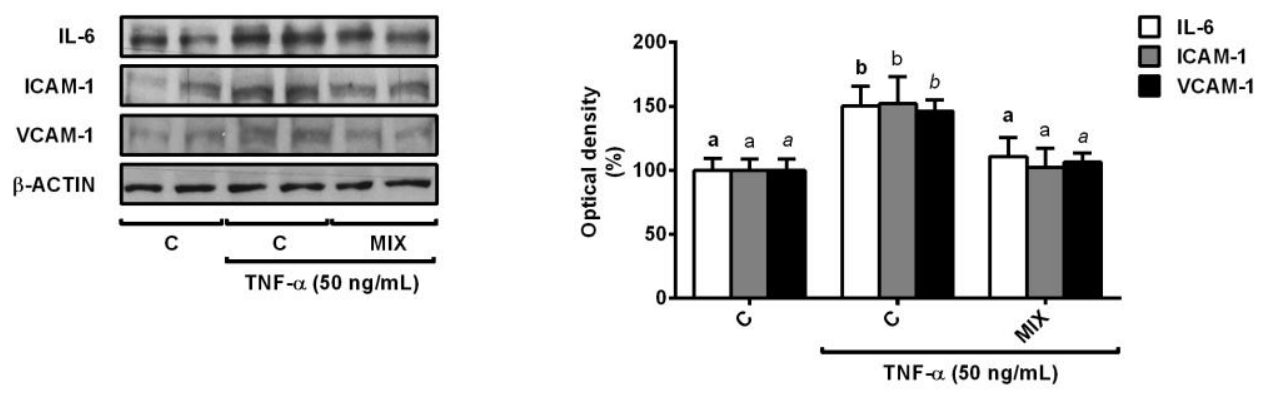

D)
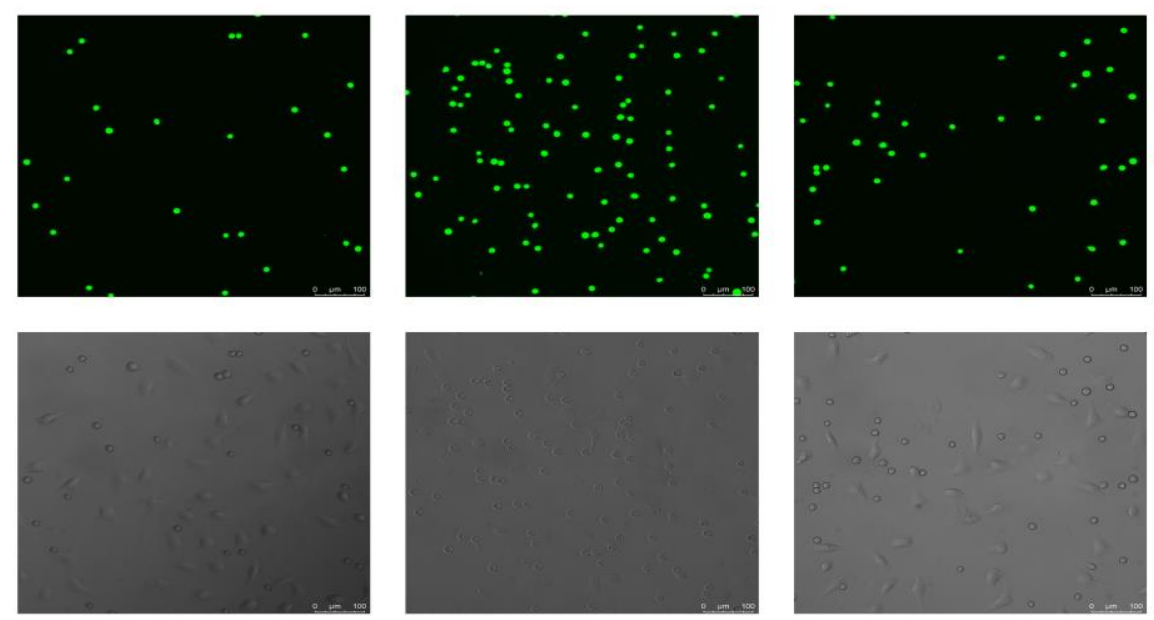

C
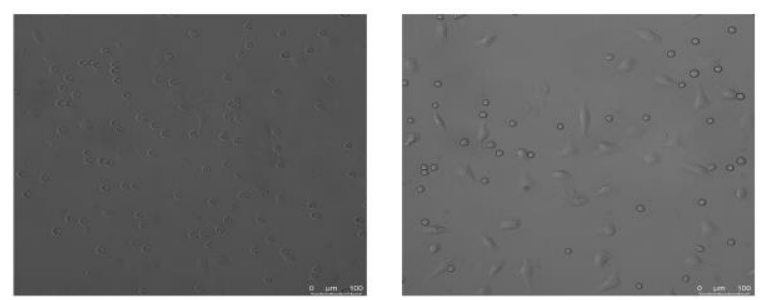

C

MIX 
Figure 6

A)

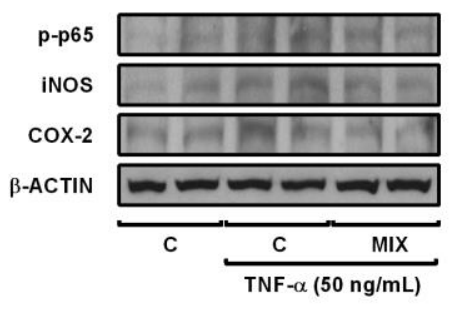

B)

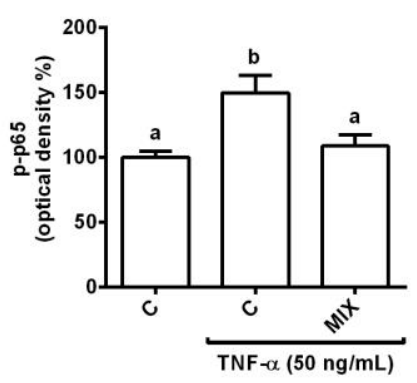

D)

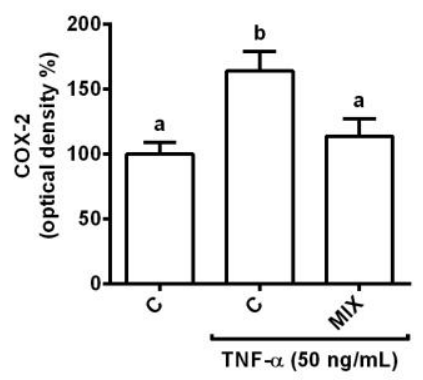

